Brit. J. industr. Med., 1954, 11, 180.

The relationship between the prolonged use of pneumatic powered tools and the development of Raynaud's phenomenon was first described by Loriga (1911), and subsequently by Hunter, McLaughlin, and Perry (1945), and by Lindqvist and Flemberg (1945). This association with high frequency vibratory tools was later extended to other industrial processes. Telford, McCann, and MacCormack (1945) and Agate (1949) described " outbreaks" in workers using flex-driven (Morrisdrive) rotary polishing tools, Middleton (1931) in workers on " pounding" machines in the boot and shoe industry, Gurdjian and Walker (1945) in those using light riveting hammers in aircraft construction, and Agate, Druett, and Tombleson (1946) in " hand-grinders" holding iron castings against revolving grinding wheels. Details of industrial techniques and the frequency and wave form of transmitted vibrations have been excellently reviewed by Agate and Druett (1947).

The object of the present investigation was to determine whether sufferers from vibratory tool Raynaud's phenomenon can be distinguished by any objective criteria from normal subjects or from those who develop this condition from some other cause (Jepson, 1951). Its natural history was considered particularly in relation to the occurrence of nutritional or organic arterial lesions in the digits. An attempt was also made to evaluate the amount of disability which it causes, not only at work but also in leisure hours.

\section{Selection of Patients}

Responsibility for the selection of patients was left with the Department of Occupational Health of Manchester University. Names were secured from trade unions, an independent medical officer, and the Ministry of Pensions and National Insurance. A questionnaire was sent to each patient.
From information given men were selected for examination in Manchester and Birmingham. Selection took into consideration the following : (1) Representation of as many operations involving vibration as possible ; (2) proximity to the examining centre; and (3) where many cases were notified from one industry the more severe were selected. This paper deals with those patients seen in the Manchester centre.

Thirteen trade unions submitted the names of 290 persons thought by their general or local secretaries to be suffering from the condition. Thirty-four men notified in this way were examined.

An industrial medical officer submitted details of 38 men working full time at clinching and flanging motor car doors. Five of the more severe cases were examined in the factory medical department.

The Ministry of Pensions and National Insurance submitted, with the patients' approval, the names of those certified as unfit for work by reason of "Raynaud's disease" or Raynaud's phenomenon. Answers to the questionnaire showed that only two patients were likely to be exposed to vibration. These two cases were included in the group. The total seen was 41,39 of whom were at work.

\section{Methods}

Patients were seen, singly by appointment, and examined during a period of two to three hours in a private office. Following an industrial and medical history a physical examination was performed with particular emphasis on the cardiovascular and musculo-skeletal systems. A haemoglobin estimation, urine examination, estimation of the erythrocyte sedimentation rate, and a radiological study of the hand, which included in every exposure the same reference metacarpal bone, allowing valid comparisons to detect minor degrees of bony rarefaction. An attempt was made to produce "white 
fingers", characteristic of Raynaud's phenomenon, by immersing the hand in cold water, and in addition a more detailed investigation of the behaviour and structure of the digital vessels was made by applying the reactive hyperaemia and heat-flow disc tests.

\section{Clinical and Occupational History}

Seven of the patients in the series were suffering from conditions not directly related to their occupation and are therefore excluded from the following analysis. The ages of the remaining 34 patients (all males) ranged from 26 to 57 years (mean, 42 years). Details of trades, ages, the interval between the start of work with the vibratory tool and the onset of the patient's complaint, and the total duration of the causative work will be found in Table 1.

TABLE 1

SUMMARY OF OCCUPATIONS AND HISTORIES OF 34 PATIENTS WITH RAYNAUD'S PHENOMENON

\begin{tabular}{|c|c|c|c|c|}
\hline \multirow{2}{*}{ Occupation } & \multirow{2}{*}{ Age } & \multicolumn{2}{|c|}{$\begin{array}{l}\text { Years of Work } \\
\text { with Vibrating } \\
\text { Tools }\end{array}$} & \multirow{2}{*}{$\begin{array}{l}\text { No. of } \\
\text { Digits } \\
\text { Involved }\end{array}$} \\
\hline & & Total & $\begin{array}{c}\text { Before } \\
\text { Onset of } \\
\text { Symptoms }\end{array}$ & \\
\hline $\begin{array}{l}\text { Pneumatic drilling in limestone, } \\
\text { granite, or gypsum (6 patients) }\end{array}$ & $\begin{array}{l}42 \\
42 \\
43 \\
44 \\
49 \\
54\end{array}$ & $\begin{array}{l}13 \\
25 \\
12 \\
24 \\
20 \\
15\end{array}$ & $\begin{array}{c}8 \\
4 \\
4 \\
4 \\
17 \\
1 \frac{1}{2}\end{array}$ & $\begin{array}{r}3 \\
4 \\
3 \\
10 \\
8 \\
10\end{array}$ \\
\hline Shoe pounding ( 4 patients) & $\begin{array}{l}26 \\
31 \\
33 \\
41\end{array}$ & $\begin{array}{r}5 \\
12 \\
5 \\
12\end{array}$ & $\begin{array}{c}2 \text { months } \\
1 \\
9 \text { months } \\
4\end{array}$ & $\begin{array}{r}10 \\
9 \\
10 \\
8\end{array}$ \\
\hline $\begin{array}{l}\text { Pneumatic chiselling in iron, } \\
\text { steel, phosphor-bronze } \\
\text { (8 patients) }\end{array}$ & $\begin{array}{l}31 \\
35 \\
36 \\
37 \\
38 \\
50 \\
52 \\
53\end{array}$ & $\begin{array}{r}5 \\
7 \\
12 \\
16 \\
17 \\
27 \\
23 \\
14\end{array}$ & $\begin{array}{c}1 \frac{1}{2} \\
1 \frac{1}{2} \\
10 \\
4 \\
10 \\
14 \\
19 \\
3\end{array}$ & $\begin{array}{l}8 \\
8 \\
7 \\
4 \\
3 \\
3 \\
2 \\
8\end{array}$ \\
\hline Pneumatic riveting ( 2 patients) & $\begin{array}{l}45 \\
53\end{array}$ & $\begin{array}{r}7 \\
26\end{array}$ & $\begin{array}{r}1 \\
20\end{array}$ & $\begin{array}{l}8 \\
8\end{array}$ \\
\hline $\begin{array}{cl}\begin{array}{c}\text { Flex-driven grinding } \\
\text { iron (4 patients) }\end{array} & \text { in steel, } \\
& \cdots\end{array}$ & $\begin{array}{l}41 \\
53 \\
53 \\
57\end{array}$ & $\begin{array}{r}4 \\
20 \\
6 \\
5\end{array}$ & $\begin{array}{c}1 \\
9 \\
3 \\
4 \text { months }\end{array}$ & $\begin{array}{r}1 \\
9 \\
10 \\
2\end{array}$ \\
\hline $\begin{array}{l}\text { Hand grinding in carborundum, } \\
\text { steel ( } 4 \text { patients) }\end{array}$ & $\begin{array}{l}39 \\
45 \\
46 \\
47\end{array}$ & $\begin{array}{r}5 \\
30 \\
7 \\
4\end{array}$ & $\begin{array}{c}27 \\
1 \frac{1}{2}\end{array}$ & $\begin{array}{l}5 \\
6 \\
8 \\
8\end{array}$ \\
\hline $\begin{array}{l}\text { Pneumatic clinching and flang- } \\
\text { ing ( } 5 \text { patients) }\end{array}$ & $\begin{array}{l}27 \\
32 \\
32 \\
40 \\
46\end{array}$ & $\begin{array}{r}1 \\
4 \\
7 \\
14 \\
20\end{array}$ & $\begin{array}{l}4 \text { months } \\
6 \underset{2^{\frac{1}{2}}}{1} \\
1 \text { month }\end{array}$ & $\begin{array}{l}3 \\
7 \\
4 \\
3 \\
5\end{array}$ \\
\hline Wire straightening ( 1 patient).. & 31 & 5 & $2 !$ & 7 \\
\hline
\end{tabular}

The onset of Raynaud's phenomenon followed a symptomless period of work with the vibratory tool which ranged from one month to 20 years. The workmen affected in any particular trade seldom included all of those handling pneumatic tools, and the duration of work before the onset of symptoms varied from man to man. Thus, among the group of 10 workers using pneumatic chisels and riveters, two patients first noticed "white fingers" within 18 months of beginning work, while for another two the interval was 19 and 20 years respectively. The period of time before onset did not appear related to a family or previous personal history of Raynaud's phenomenon, the degree of exposure to cold at work, age, or anatomical type of fingers. Patients in some trades, such as flangers and clinchers in the motor industry and shoe pounders, were particularly liable to develop it. A survey of 38 full-time clinchers, $100 \%$ of those thus employed at one factory (five of whom are included in the present series), showed that four had no symptoms, 23 developed symptoms within one year, five within two years, four within three years, and two in a period at work of more than three years. By contrast, five of the six limestone and gypsum workers interviewed noticed the onset after a period of four to 17 years' drilling.

It is common to all of the trades examined in this review for the onset to be earlier and for the condition to be more severe in fingers to which most vibration is transmitted. For example (in righthanded workers) the flex-driven grinding machine is gripped and guided near the grinding end by the little, ring, and middle fingers of the left hand. It was in these fingers that Raynaud's phenomenon inevitably first developed. In the pounding process employed in the boot and shoe industry the sole is held by both hands equally, being gripped most firmly by the thumbs and forefingers as it is pressed against the pounding roller. These workers develop Raynaud's phenomenon simultaneously and symmetrically in the thumbs and forefingers of both hands. The fingers less directly involved by the vibratory stimuli are affected much later on.

The severity of attacks of "white fingers", that is the facility with which they are induced and their persistence, appears to reach a maximum some years after their onset and thereafter further exposure does not appreciably increase the severity. Thus T. H., a shoe pounder, developed symptoms within one year of starting this work. Attacks became more frequent and prolonged over the next two to three years and then remained unchanged for the following nine years of similar employment.

Thirteen patients had abandoned the causative trade from one to nine years (mean, four years) before interview; three because of Raynaud's 
phenomenon, seven because of redundancy, and three by promotion. With one exception, they stated that attacks persisted unchanged or became more severe and frequent after their change of employment. One patient who worked as a clincher for four years developed symptoms only after he had ceased to use the pneumatic tool.

Patients complained that attacks of white " dead " fingers were most noticeable in the winter months, in early mornings on rising, and during outdoor activities such as going to football matches, fishing, or gardening. Washing the hands in cold water was frequently said to be a precipitating cause. Relief was obtained by warming affected fingers in hot water, by friction or radiant heat. Attacks in the initial stages of the disorder involved only the terminal segment of a finger. Later the whole digit became blanched to the metacarpo-phalangeal joint and additional fingers were affected. The "white" phase was accompanied by cold ache and numbness. Relaxation of the digital vessels was followed by periods of digital cyanosis and the pinkness and paraesthesiae of reactive hyperaemia.

Hands recovered completely between attacks and were of normal colour and warmth, in contrast to the usual high peripheral tone or cyanosis seen in other cases of Raynaud's phenomenon. None of the patients complained of nutritional lesions in digits such as soft tissue wasting, ulcers, or gangrene.

Raynaud's phenomenon rarely interfered to a marked degree with the patient's work. This was particularly true of those working indoors in a warm atmosphere as both body and finger temperatures were higher than that required to precipitate an attack. In outdoor workers, for example limestone drillers, numbness, clumsiness, and an ache in the fingers during cold winter months compelled them to seek frequent relief from a neighbouring brazier. The mean period of work in causative trades for the 34 patients following the onset of symptoms was seven years (range one to 21 years). Loss of time or earnings was not a frequent or dominant complaint. All patients, however, complained of considerable handicap during their leisure hours in as much as their pleasure in gardening, swimming, and watching or playing outdoor games was impaired by numb or painful fingers.

Seven patients (excluded from the 34 patients reviewed above) claimed to be totally incapacitated by this condition. These patients (six men and one woman) were without exception suffering from other conditions which could not properly be attributed to their occupations, namely, generalized atherosclerosis (two), acrosclerosis (one), rheumatoid arthritis (one), athetosis (one), writer's cramp (one). One patient was thought to be a malingerer.

\section{Physical Examinations}

None of the 34 patients was found to have any neurological or connective tissue disease but two had a mild hypertension. The peripheral limb pulses were present and of good volume. $X$-ray examination of wrists and hands demonstrated carpal or metacarpal cysts in four patients although in none were symptoms referred to the carpal region. Haemoglobin, erythrocyte sedimentation rate, and urinary examinations were normal.

Accessory Tests. - These tests were designed to determine whether the lumina of the digital arteries were normally patent in the intervals between vasospastic attacks and whether an abnormal reaction by the digital vessels to finger cooling could be demonstrated objectively. The lightly clothed patient was rested before examination for 45 to 60 minutes in a constant temperature room $\left(21^{\circ} \mathrm{C}\right.$.).

Reactive Hyperaemia Test.-This was used to exclude gross organic occlusion in the digital arteries (Pickering, 1933).

The hands were immersed to the wrist in a water bath at $40^{\circ} \mathrm{C}$. for five minutes; arterial occlusion was maintained by means of a sphygmomanometer cuff on the upper arm. At the end of this time the hands were removed from the water and on releasing the cuff a pink flush spreading symmetrically to the tips of the digits within four seconds was taken to be evidence that the lumina of the digital arteries were normally patent. All of the 34 patients were found to be normal by this criterion.

Precipitation of Raynaud's Phenomenon by Hand Cooling.-The hands were immersed in a stirred water bath at $15^{\circ} \mathrm{C}$. for 15 minutes; during the first five minutes the circulation was occluded with a sphygmomanometer cuff on the upper arm to ensure rapid cooling of the digits. Fourteen of the 34 patients tested developed white " dead" fingers, typical of Raynaud's phenomenon, in one or more digits. Many of the remaining 20 developed a varying degree of cyanosis in the digits, the significance of which could not be evaluated (Table 2).

TABLE 2

EFFECT OF HAND COOLING IN 34 PATIENTS

\begin{tabular}{c|c|c|c}
\hline $\begin{array}{c}\text { Age } \\
\text { (years) }\end{array}$ & $\begin{array}{c}\text { No. of } \\
\text { Subjects }\end{array}$ & $\begin{array}{c}\text { Precipitation of } \\
\text { White Finger" }\end{array}$ & $\begin{array}{c}\text { Absence of } \\
\text { "White Finger " } \\
\pm \text { Cyanosis }\end{array}$ \\
\hline $20-39$ & 13 & 6 & 7 \\
\hline $40-59$ & 21 & 8 & 13 \\
\hline
\end{tabular}


Heat-flow Test.-This test was designed to estimate the reactions of the digital and skin blood vessels to cold by measuring the heat-flow (in calories per square centimetre of skin per minute) from the skin covering the pulp space of an affected finger by means of a copper-tellurium heat-flow disc (Hatfield, 1950 ; Catchpole and Jepson, 1954). The disc was attached to the finger with cellulose tape and the whole hand immersed in continuously stirred water of $15^{\circ} \mathrm{C}$. while the circulation was occluded by a sphygmomanometer cuff on the upper arm. The heat loss from the finger to the water was recorded by a spot galvanometer $(450 \mathrm{ohms})$. At the end of five minutes' immersion the heat exchange between the finger skin and the water had virtually ceased (galvanometer reading less than 10 divs.). The cuff was then removed, the hand remaining immersed in the water bath for a further 10 minutes. If the digital arteries reacted to the cooling by spasm then no blood could pass into the fingers on release of the cuff and the heat flow between the skin and the water approximated to zero (negative test). Alternatively if the vessels responded to the vasodilator stimulus of arterial occlusion (Lewis and Grant, 1925 ) then relaxation occurred and a varying degree of increase of heat flow from the finger to the water bath was detected (positive test).

Twenty-four patients and 29 normal controls were investigated by the heat flow disc test (Table 3).

TABLE 3

RESULTS OF HEAT-FLOW DISC TEST IN PATIENTS WITH VIBRATORY TOOL RAYNAUD'S PHENOMENON AND NOR MAL CONTROLS

\begin{tabular}{c|c|c|c|c}
\hline \multirow{2}{*}{ Age } & \multicolumn{2}{|c|}{ Patients } & \multicolumn{2}{c}{ Normal Controls } \\
\cline { 2 - 4 } \cline { 4 - 5 } & No. & $\begin{array}{c}\text { Negative } \\
\text { Result* }\end{array}$ & No. & $\begin{array}{c}\text { Negative } \\
\text { Result }\end{array}$ \\
\hline $20-39$ & 11 & 7 & 17 & 1 \\
$40-59$ & 13 & 6 & 12 & 7 \\
\hline Total & 24 & 13 & 29 & 8 \\
\hline
\end{tabular}

*Negative result means here persistent spasm.

Thirteen patients and eight controls gave a negative test indicative of vascular spasm. In the remainder of both patients and controls the test was positive. Among the 24 patients visible "white fingers" were demonstrated by the cooling test in nine and a "white finger" was constantly accompanied by a negative heat-flow test. The significance of the test and the findings in normal and abnormal cases are discussed in detail elsewhere (Jepson, 1954).

\section{Discussion}

There can be no doubt that long-continued use of a certain type of vibratory tool eventually leads to Raynaud's phenomenon in the fingers. Comparative figures are not available of the incidence of this condition in different trades, but in many its onset is early and its incidence high. Thirty-two of 37 hand grinders developed it within 21 months (Agate and others, 1946); 184 of 278 workers scrufing and polishing metal castings with rotary hand tools were affected (Agate, 1949). As recorded above, 23 out of 38 clinchers and flangers developed it within one year of starting this type of work.

The physical conditions which bring about the change of behaviour in the digital arteries are partially defined. Agate and Druett (1947) by using a piezo-crystal recording technique suggested that critical frequencies leading to Raynaud's phenomenon were about 40 to 125 cycles per second. Many other variables may be of equal or greater importance such as amplitude and wave form of fundamental and secondary harmonics, strength of grip required, type of material on which work is performed, the operator's skill, the mechanical efficiency and mass of the tool, and each individual's susceptibility to the condition.

The pathological lesion which the high frequency physical trauma produces is unknown. Histological studies have not, as far as is known, been made, since amputation of affected digits is not required. The absence of nutritional lesions in the vibratory tool form of Raynaud's phenomenon suggests that the abnormality is confined to the muscle of the media and does not include endothelial proliferation with encroachment upon the lumen. The malady appears to be limited to a behavioural change on the part of the digital vessels in response to cooling, and long-continued work with causative tools does not lead to the onset of narrowing or blockage of the digital artery. This conclusion was also reached clinically by Hunt (1936), Lindqvist and Flemberg (1945), Telford and others (1945), and Agate (1949), and is confirmed in the present study by the lack of nutritional lesions and the normal reactive hyperaemia tests. Arteriography in many similar patients has previously demonstrated normal vessel patterns (Jepson, 1951). It is emphasized that the group of seven patients who claimed to be incapacitated by Raynaud's phenomenon were in fact suffering from general systemic diseases totally unconnected with the use of vibratory tools. It is evident that certain tools may indeed cause other and more severely disabling traumatic lesions but these differ in nature and possibly in precise cause from Raynaud's 
phenomenon. For example, the group of five clinchers and flangers examined in this series all showed evidence of digital nerve lesions, joint pain and swelling, and cramp or weakness in the long flexor muscles. Dart (1946) and Peters (1946) have reported similar symptoms in men using air-turbine driven grinding tools. Agate and Druett (1947) suggested that frequencies above 160 cycles per second may cause this latter clinical picture.

It is apparent that the vascular tests used to confirm the presence of Raynaud's phenomenon have proved disappointing. In many instances cooling fails to provoke visible evidence of spasm of the digital artery in patients who are undoubtedly suffering from attacks of Raynaud's phenomenon. Such patients seem to need supplementary stimulus of vasoconstrictor activity from body cooling before the digital colour change can be produced. Although the proportion of confirmatory results is slightly higher with the heat-flow disc test than with the visual test, the issue is further complicated by the frequency with which a control sample of normal adults, especially in the older age groups, give a negative heat-flow test indicative of vascular spasm (Jepson, 1954). Nor does the objective confirmation of vascular spasm allow a diagnosis to be made of Raynaud's phenomenon due to the use of a vibratory tool. Its onset in adult life secondary to an underlying disease process is most commonly due to atherosclerosis, thromboangiitis obliterans, or a form of rheumatoid arthritis. Attacks of " white fingers" seen in workers with vibratory tools do not in themselves differ essentially from many attacks due to other causes. There are, however, some associated features which are characteristic of this condition when it is due to the use of vibratory tools and assist in the diagnosis; the onset is related to a particular type of work involving the transmission to the hands of high frequency vibrations; there is an earlier and more severe form in fingers to which most vibration is transmitted, and it is therefore usually asymmetrical in development but can sometimes be equally distributed in both hands as in the shoe-pounder. The lumina of the digital arteries are not occluded and there are no nutritional lesions in the fingers. Primary arterial disease and rheumatoid arthritis are absent.

The degree of disability varies considerably because of variations in the severity of Raynaud's phenomenon and by reason of the man's type of work and hobbies. It is evident that among those working in heated buildings time or wages are seldom lost. In those working out of doors, particularly limestone drillers, much time may be spent warming the hands at a neighbouring fire. Considerable discomfort may be experienced from cold-ache associated with " white fingers". Two major complaints are the handicap which the disability causes in the enjoyment of outdoor recreations and the difficulties involved when the patient changes his job to one necessitating fine finger control. In such circumstances there may be considerable disability and one which, as far as can be ascertained, is unlikely to improve with the passage of time.

\section{Summary}

Forty-one patients from various trades thought to be suffering from Raynaud's phenomenon caused by vibratory tools were investigated. Seven of the patients were suffering from some other condition which could not possibly be attributed to this type of work.

In the remaining 34 patients vascular tests exclude organic occlusive lesions, and in approximately one half of the cases confirmed the liability to Raynaud's phenomenon. The value of tests was limited by false positive and negative results in patients and normal controls. The diagnosis of Raynaud's phenomenon caused by vibratory tools must therefore at present be made on clinical grounds.

The use of some forms of vibratory tool leads to a much higher incidence of Raynaud's phenomenon with earlier onset than does the use of other forms of tool. In occasional instances, nearly all the individuals exposed for one or more years are affected.

The severity of the Raynaud's phenomenon reaches a maximum within a few years of its first appearance and further exposure does not apparently change its severity.

There is little evidence to suggest that Raynaud's phenomenon, once established, will disappear or appreciably abate in severity even though the patient abstains from the causative employment.

Raynaud's phenomenon rarely interferes to a marked degree with the patient's work. It may, however, limit the enjoyment of his leisure to the extent that gardening, swimming, and the observation of or participation in outdoor games may be impaired by reason of numb or painful fingers.

I am indebted to Professor R. E. Lane and Miss N. M. Goodman, of the University Department of Occupational Health, who have undertaken all the gruelling staff work required to organize this survey, to Dr. Raynard for the details of the survey of the clinchers in the motor industry, and to Professor Boyd in whose department the investigations were carried out. 
The travelling costs of patients were defrayed by the Ministry of Pensions and National Insurance.

\section{REFERENCES}

Agate, J. N. (1949). British Journal of Industrial Medicine, 6, 144. and Druett, H. A. (1947). Ibid, 4, 141 .

-, and Druett, H. A. (1947). Ibid, 4, 141, ibid, 3, 167

Catchpole, B. N., and Jepson, R. P. (1954). Circulation, 9, 408.

Dart, E. E. (1946). Occup. Med., 1, 515.

Gurdjian, E. S., and Walker, L. W. (1945). J. Amer. med. Ass., 129 668.

Hatfield, H. S. (1950). J. Physiol., Lond., 111, 10P.

Hunt, J. H. (1936). Proc. roy. Soc. Med., 30, 171.
Hunter, D., McLaughlin, A. I. G., and Perry, K. M. A. (1945) British Journal of Industrial Medicine, 2, 10.

Jepson, R. P. (1951). Ann. roy. Coll. Surg. Engl., 9, 35.

(1954). Clin. Sci., 13, 259.

Lewis, T., and Grant, R. (1925). Heart, 12, 73.

Lindqvist, T., and Flemberg, T. (1945). Acta med. scand., 121, 309.

Loriga, G. (1911). Quoted by Teleky, L. "Pneumatic Tools." Occupation and Health. Supplement (Sept., 1938), International Labour Office, Geneva.

Middleton, E. L. (1931). Ann. Rep. H.M. Chief Insp. Fact. 1930, p. 119.

Peters, F. M. (1946). Occup. Med., 2, 55.

Pickering, G. W. (1933). Brit. med. J., 2, 1106.

Telford, E. D., McCann, M. B., and MacCormack, D. H. (1945). Lancet, $2,359$. 